\title{
Control and optimization of the refrigeration plant in a brewery
}

\author{
Petersen, P.M; Qvale, Einar Bjørn
}

Published in:

Proceedings of the 24th Intersociety Energy Conversion Engineering Conference

Link to article, DOI:

10.1109/IECEC.1989.74717

Publication date:

1989

Document Version

Publisher's PDF, also known as Version of record

Link back to DTU Orbit

Citation (APA):

Petersen, P. M., \& Qvale, E. B. (1989). Control and optimization of the refrigeration plant in a brewery. In Proceedings of the 24th Intersociety Energy Conversion Engineering Conference (Vol. Volume 4, pp. 18071812). IEEE. https://doi.org/10.1109/IECEC.1989.74717

\section{General rights}

Copyright and moral rights for the publications made accessible in the public portal are retained by the authors and/or other copyright owners and it is a condition of accessing publications that users recognise and abide by the legal requirements associated with these rights.

- Users may download and print one copy of any publication from the public portal for the purpose of private study or research.

- You may not further distribute the material or use it for any profit-making activity or commercial gain

- You may freely distribute the URL identifying the publication in the public portal 
CONTROL AND OPTIMIZATION OF THE REFRIGERATION

PLANT IN A BREWERY

\author{
P.M.Petersen and B.Qvale \\ Laboratory for Energetics \\ The Technical University of Denmark
}

\section{ABSTRACT}

The design and operation of a refrigeration plant in a brewery has been studied. The plant has been evaluated by using mathematical models of the components to simulate responses to real-life load variations.

The study shows, that the effiency and economy for the actual refrigeration plant could be improved significantly by a combination of three different approaches: design optimization, improved operation strategy and load management.

The improvements obtainable by each approach and by combinations of these are reported.

A reduction of primary fuel consumption of $15 \%$ is obtainable ideally, while a realistic practical goal is $10 \%$.

\section{INTRODUCTION}

Industrial energy systems are often characterized by complex designs and highly fluctuating loads, caused by numerous consumers and subsystems. These characteristics make analysis and overall optimization of the design and operation of an complex energy system an extensive and time consuming work. A plant is described by a large number of design variables and should be evaluated in many load points in order to determine an absolute best economy for a plant.

Furthermore, an overall optimization of a complex energy system is not well defined from a mathematical point of view. Often basically different system designs must be compared. This problem is discrete and non-linear, which turns an overall optimization into a combinatorial problem rather than a continuous mathematical problem.

However, as eneroy prices rose during the nineteenseventies, a considerable effort was invested in reducing the consumption of primary fuel and in developing improved design methods for energyintensive industries. Although the fuel prices have decreased during the eighties, this effort has been continued. With an increased emphasis on environmental issues during the next decades, these activities will increase in importance.

\title{
899409
}

Still, not many studies of optimization methods and applications of these have been reported. Energy conversion plants have been studied [1]-[3], but the results can not be compared because of the completely different methods used and because of the much different energy demands, economics, envirommental conditions etc. One second law study [1] shows, that the optimum distribution of the heattransfer area in evaporator and condenser for conventionel heat pumps is independent of temperatures, Carnot efficiency and heat-transfer coefficients, but does not attempt to find the optimal distribution for various system configurations. Another one, [2], gives some "rules of thumb" for the placement of heat pumps relative to heat-exchanger networks, but does not consider the optimization of the heat purmp itself.

In general, optimization studies of the above type usually only consider single load points. But partload operation is the most frequent operating mode in many energy systems. As important operating conditions change hourly, daily, and annually, realistic load series should be used. Even if most of the fuel consumption occurs at high loads, poor part load operation will significantly impair the total economy of a plant.

Therefore, for the evaluation of complex energy systems, simulation techniques may represent the most useful tool. Using mathematical descriptions of performance curves for important components in a system and real-life load series, different designs and operational strategies can be evaluated and compared. Widely different system configurations and operational strategies can be tested and a best overall desion and performance can be obtained. But it is difficult to generalize the results. At best, the results contribute to the pool of experiences resulting from such simulation studies. The present work belongs to this last type of investigations.

\section{THE REFRIGERATION PLANT}

The refrigeration plant studied is operating at a brewery near Copenhagen, Dermark. The plant is using ammonia as refrigerant and delivers saturated armionia at high pressure for cooling purposes for the entire brewery, e.g. in the brewing processes, fermentation tanks, storage rooms etc. The ammonia is evaporated locally at two pressures, corresponding to cooling needs at $-6^{\circ} \mathrm{C}$ and $-10^{\circ} \mathrm{C}$. 
The condensers are common to the two systems operated at these two evaporator pressures. In total, an amount of 45 tons of ammonia is circulating in the refrigerant system. The power consumed by compressors and pumps is $3700 \mathrm{Mm} /$ /year.

The needs for cooling in each system varies with the operation of the principal brewing processes, and the loads vary widely througout the week and the year. The cooling loads in each utility system have been measured every thirty second during half a year [4] and the data have been averaged over two hours. The load profiles in the two systems for a week in August are shown in figure $1 \mathrm{a}$ and $1 b$,

$Q_{6}[\mathrm{KJ} / \mathrm{s}]$

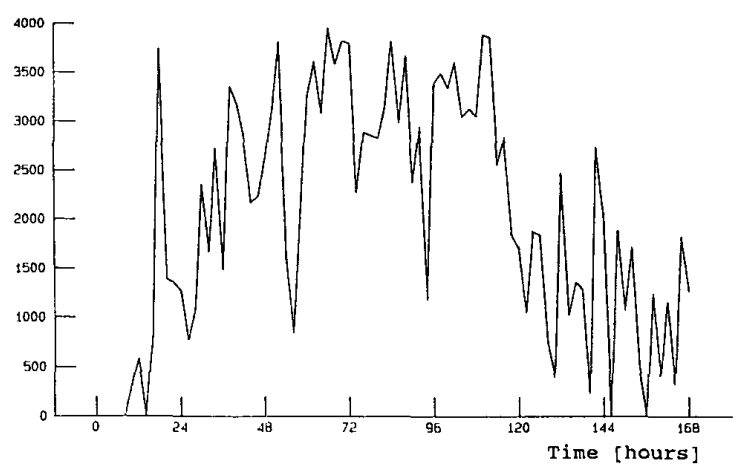

Figure 1a. Demand variations at $-6^{\circ} \mathrm{C}$ during a week in August.

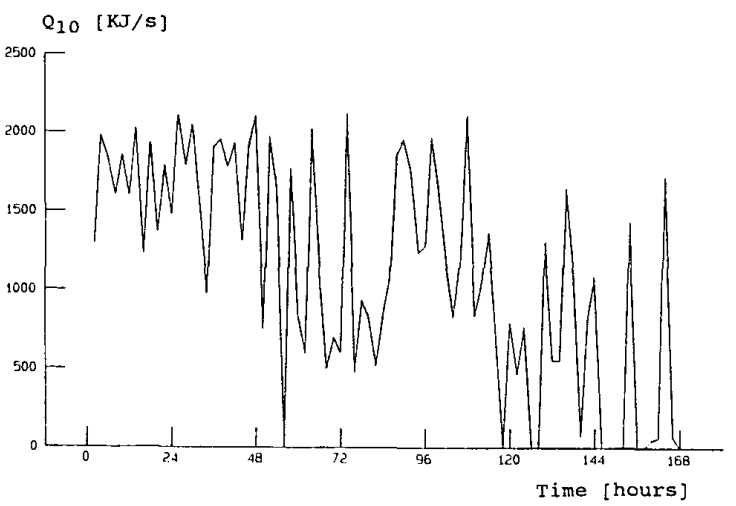

Figure 1b. Demand variations at $-10^{\circ} \mathrm{C}$ during a week in August.

During winter operation (February), the loads are approximately halved compared to the loads in August.

To insure a satisfactory operation and effiency at all loads, the refrigeration plant is designed with a number of condensers (9), high-efficiency screw compressors (3) and low-efficiency reciprocating compressors (4), and a number of pumps (3) and pipes (2) for pumping sea-water.
The management of these components is handled by a control system, where simple strategies for how to operate and combine compressors, condensers and pumps as the load varies are implemented. The principal concerns are the efficiency of the screw compressors and the part-load performance of the reciprocating compressors. As the thermal capacity of the utility systems is small relative to the loads, part load is the most common operating mode for the compressors.

The plant also contains other components as receivers, buffers and valves [4].

\section{System model}

A mathematical simulation model has been developed in order to evaluate the system performance and to investigate alternative system designs and management strategies. The real load-series have been inferred from the production (KJ/s) of the compressors. The total system can therefore be described without considering the detailed design of the utility systems and without considering the dynamics of the distribution system. A quasi-static description of compressors, pumps and condensers will then be sufficient to simulate and evaluate different system designs and operating strategies.

The simulation model contains mathematical descriptions of each of the main components in the refrigeration plant. These descriptions represent curve fits of empirical data [4]. These performances are given at part-load and full-load operation as function of the most important operating condition of the plant, the sea-water temperature.

\section{Simulated performance}

The mathematical model is used to simulate the system performance. The components to be in service in each load situation are selected by the same criteria as by the present control system. An example of the resulting coefficient of performance (COP) for the total refrigeration plant as a function of the load in the $-6^{\circ} \mathrm{C}$ system for two values of the load in the $-10^{\circ} \mathrm{C}$ system is shown in figure 2.

The sudden changes in the curves are caused by varying selection of compressors, condensers and sea-water pumps with changing loads in the $-6^{\circ} \mathrm{C}$ system. It is seen, that the COP will vary significantly when using the present operating strategy and that the best efficiency is obtained at a load of approximately $1500 \mathrm{~kJ} / \mathrm{s}$, corresponding to fullload operation of one screw compressor. When the reciprocating compressors are used and at partload, the COP of the system is lower. In addition, several COP values are low because of a poor matching between the power consumption for the seawater system and the compressors. 


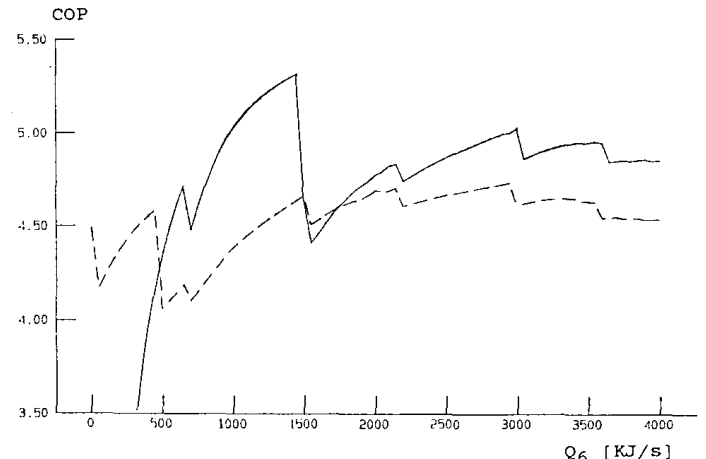

Figure 2. COP for the refrigeration plant as the load increases in the $-6^{\circ} \mathrm{C}$ system, subject to sea-water conditions in August. $(\longrightarrow): Q_{10}=00 \mathrm{KJ} / \mathrm{s}$.

A load profile has been simulated for a week in August, and the COP variation during the week is shown in figure 3.

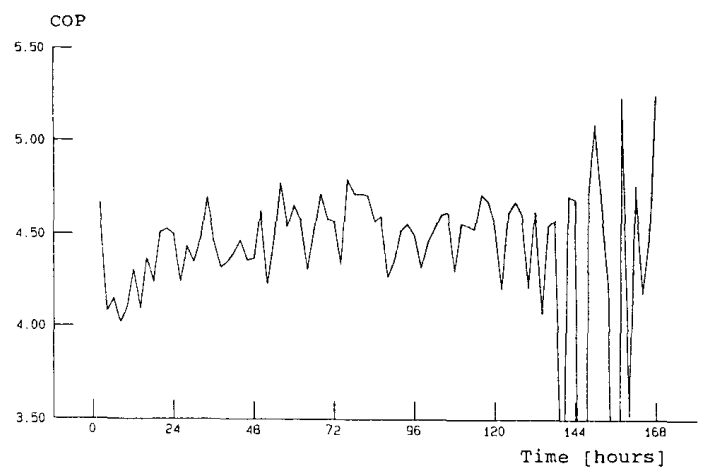

Figure 3. COP variation for the refrigeration plant during a week in August.

It is seen that the system COP shows large variations during the week. This is mainly explained by the influence of the load variations in the $-10^{\circ} \mathrm{C}$ system (the lower evaporation temperature in this system results in a lower COP). Secondly, the COP fluctuates because of changes in selection of components as seen in figure 2. Several of the lower values are caused by extreme part-load operation of the compressors.

The weekly power consumption in August is found to be 119.2 MWh. In February, the weekly power consumption is found to be 43.1 MWh.

\section{MANAGEMENT AND OPTIMIZATION OF THE PL.ANT}

The results in figures 2 and 3 illustrate how the fluctuating loads lead to a reduced overall efficiency of the refrigeration plant. Compressors must often be operated at part load and it is often necessary to operate several reciprocating compressors to meet the required cooling. In both situations, the overall efficiency is reduced.

The fluctuating loads, furthermore, make it impractical to design a plant with a highest possible efficiency at all loads. This would require an inordinately large number of components. In the existing refrigeration plant, the sea-water system and the compressors can only be operated together at their best efficiency in narrow load intervals, because of the required accurate control of the sea-water flow that is necessary in order to minimize the condenser temperature in each load situation. In order to obtain the highest efficiency at all loads, it would be necessary with several different sea-water flows and an advanced strategy to manage these. The strategy and system required to achieve an absolute best performance would be too complicated and expensive in most contexts.

The idealized operation of the plant will now be considered in order to establish the reasonable targets for an improved design and operation.

\section{Targets for an improved design and operation}

The targets for an improved design and operation of the refrigeration plant can be established by considering the average loads in each utility system during the week. This would be the ideal load situation for the plant, and the plant could be designed with a maximum efficiency corresponding to this operation.

When the refrigerant plant is optimized for this constant operation, the weekly power consumption would be 104.5 MWh in August. In February, the weekly power consumption would be $34.1 \mathrm{MWh}$. Compared to the actual consumption, the max. obtainable reductions are $12.3 \%$ in August and $20.9 \%$ in February. The annual power consumption would be reduced by $15.6 \%$

\section{Optimal desion and management of the plant}

The weekly load profile has been simulated for various designs of the plant and for various strategies for how to manage the components.

The design optimization is performed by evaluating different existing sizes of the screw compressors and the sea-water pumps, all with performance curves corresponding to the present components. To insure a proper operation at all loads, both summer and winter weeks have been simulated. For the operation of the components, the present (simple) strategy is compared to an advanced strategy. During the present operation of the plant, two screw compressors are kept constantly on alert in the $-6^{\circ} \mathrm{C}$ system and one is kept on alert in the $-10^{\circ} \mathrm{C}$ system. With the advanced stra- 


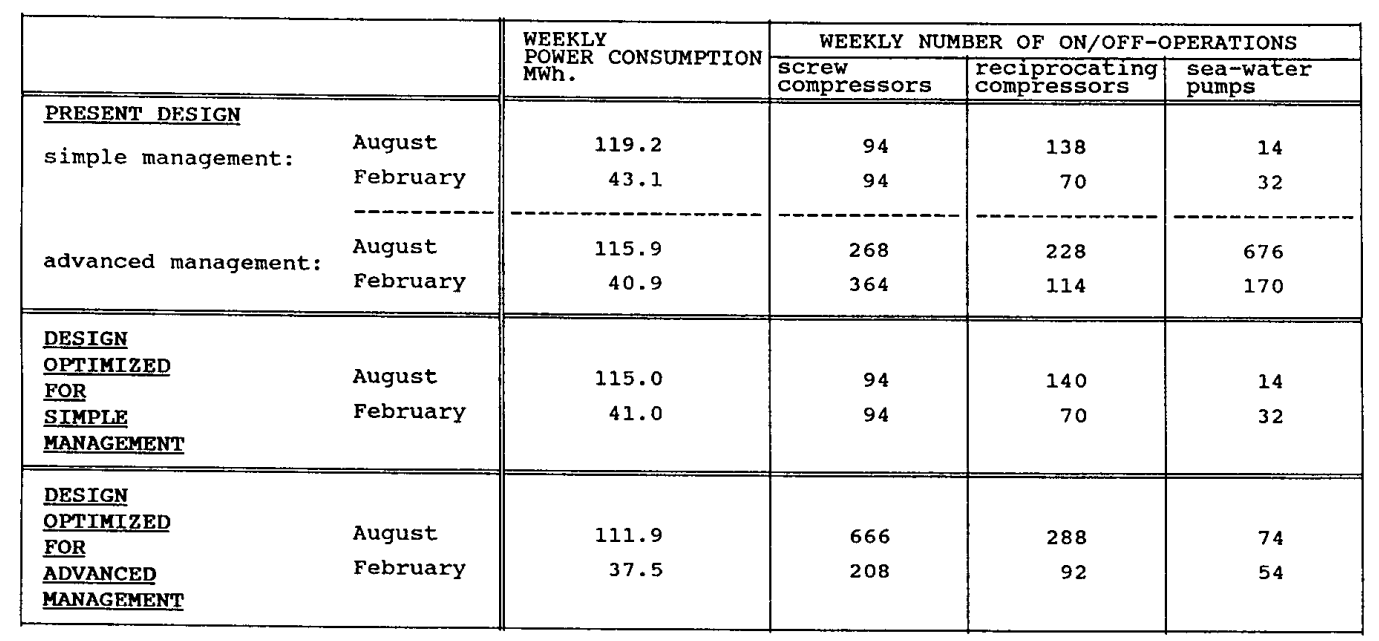

Table 1. Weekly power consumption and weekly number of oN/oFF-operations
for various optimized designs and management strategies.

tegy, the best combinations of compressors, pumps and condensers are selected in each load situation, and the screw compressors are allowed to alternate between the two utility systems.

The results are shown in table 1, where the weekly power consumption and number of $\mathrm{ON} / \mathrm{OFF}$-operations of the components are listed. In order to abtain the practical number of ON/OFF-operations, the plant has been simulated in steps of 15 minutes assuming linear changes in the loads between the recorded 2 hour loads.

It is seen, that for the existing plant, an absolute best management of the components in each load situation leads to a modest reduction of the power consumption. In total, this management of the components leads to an annual saving of $3.7 \%$.

However, the weekly number of ON/OFF-operations of the screw compressors is more than doubled relative to the present numbers, which is a critical increase. Frequent ON/OFF-operations lead to stresses in the components and hereby to a reduced reliability of the plant. Especially the sea-water pumps must be started and stopped frequently in order to keep the condenser temperature low.

If the design of a plant that is operated with the simple (present) management strategy is optimized, the weekly power consumption would be $115.0 \mathrm{MWh}$ in August and $41.0 \mathrm{Mwh}$ in February. In total, the annual power consumption is reduced by $4.0 \%$ without increasing the number of ON/OFF-operations of the components. This improvement is obtained solely by a better matching of pipes and pumps in the seawater system leading to lower flow friction and hence reduced power consumption of the pumps.

An optimization of the plant design with an advanced management of the components results in a design that differs significantly from the optimal design abtained with a simple management. First the screw compressors should be of different sizes. Second, the sea-water pumps are found to be relatively small compared to the previous simplemanagement case. By the new design, the pumps are ordered sequentially in or out of operation as the load changes.

Simulating a week in August, the weekly power consumption is reduced to $111.9 \mathrm{MWh}$; in February the power consumption is 37.5 MWh. In all an annual reduction of $8.8 \%$ is obtained, which is approximately half of the gains established as the target.

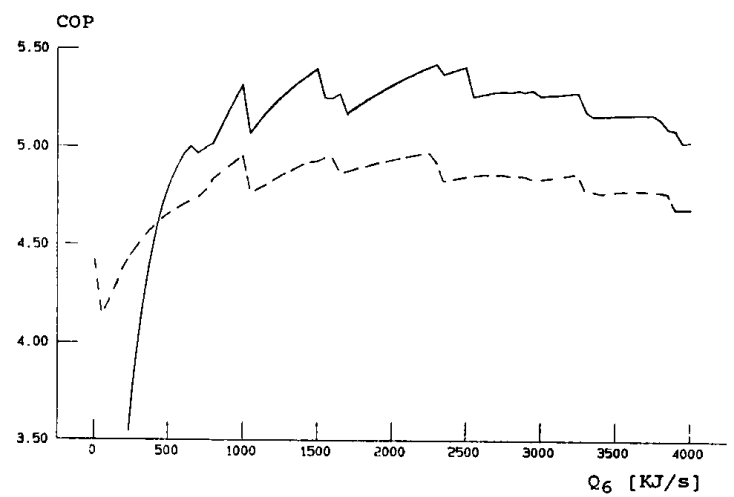

Figure 4. OP for an optimized design of the plant (with advanced management) with increasing load in the $-6^{\circ} \mathrm{C}$ system. August. $(\longrightarrow): Q_{10}=0 \mathrm{~kJ} / \mathrm{s}$

For this design and operation of the plant, the COPcharacteristic with increasing load in the $-6^{\circ} \mathrm{C}$ system is shown in figure 4. 
Compared to figure 2, it is seen that the COP is raised significantly, particularly at low loads, and that the sudden changes with varying loads are smoothed noticeably. However, the required number of ON/OFF-operations of the screw compressors is very high and would not be acceptable.

\section{Load management}

For the design and operation of the existing plant, figure 2 shows that even small changes in loads can involve changes in component selection and therefore lead to significant changes in COP. By managing the load fluctuations, the plant can be made to operate on the best side of these sudden changes in COP, thus improving the COP.

In all there are more than 500 consumers and several of these are fermentation and storage tanks with a high thermal capacity. These, and several other consumers, are cooled discontinuously in short periods (ON/OFF), and their operation is presently not coordinated and is practically random. It is in this study assumed possible to perform a limited coordination of these consumers.

The weekly load profile has been simulated for the designs and management strategies listed in table 1 assuming different possibilities for a load management in the brewery. The extent of this management is expressed as the percentage of the loads (expressed by the weekly average loads), that could be advanced or delayed for a 2 hour period when following the present weekly load profiles in each utility system. At a load management of $20 \%$ a load of $400 \mathrm{~kJ} / \mathrm{s}$ could be shifted in the $-6^{\circ} \mathrm{C}$ system when following the weekly load profile in August.

The optimal strategy for the load management is found by two-dimensional dymamic programming [5]. The problem is two-dimensional because of the strong coupling between the two utility systems, both through the condensers and the screw compressors.

In figure 5, the weekly power consumption in August is shown for each of the optimized designs listed in table 1 with increasing degree of a load management in each utility system.

In the figure it is seen that both for simple and advanced management of the components, even a modest load management results in a significant reduction in the weekly power consumption. For larger values, the simple design and management of the plant approaches the power consumption obtained for the advanced design and operation.

It is seen that the targets are not reached. This is explained by the limited capacity of the seawater system (condensers and pumps) at high loads, which leads to a reduced COP. These high loads could be avoided and the target from section 4.1 reached, if the load management were increased.

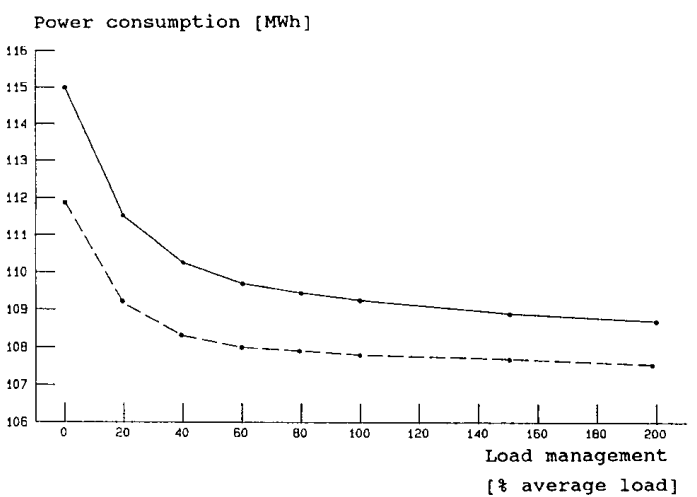

Figure 5. Weekly power consumption in August with increasing degree of load management. $(\longrightarrow)$ : simple design and operation.

(---) : advanced design and operation.

In figure 6 , the effect of the load management during winter operation is shown.

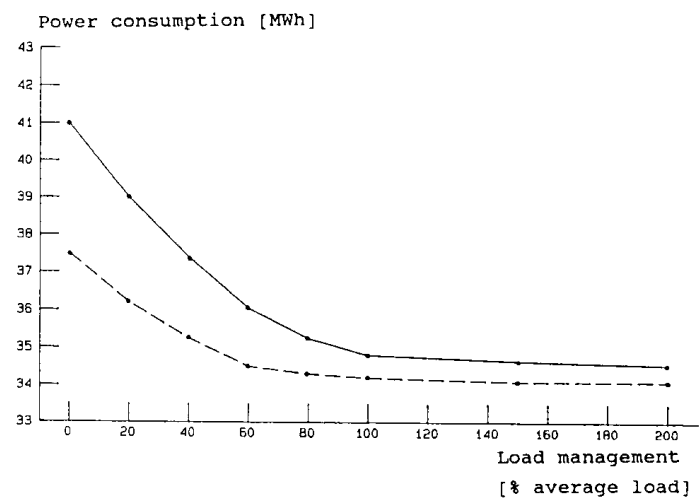

Figure 6. Weekly power consumption in February with increasing degree of load management. $(-)$ : simple design and operation. (---) : advanced design and operation.

For the winter operation it is seen, that a relative larger improvement is obtainable. Again, the gains by using load management are higher for a plant with a simple operational strategy than with advanced management. It is seen, that during winter operation, the target is obtainable for the values of load management investigated.

It is equally important, that the weekly number of ON/OFF-operations of the components is reduced when operating the plant with load management. However, with the advanced management of the components it would be necessary with extensive load management to reduce the weekly number of ON/OFF-operations to the present numbers. At the highest values of load management shown in figures 5 and 6 , the weekly 
number of ON/OFF-operations of the screw compressors is approximately $40 \%$ higher than the present.

\section{A practical, combined approach}

For a realistic, practical improved design and operation of the refrigeration plant, it is necessary. to combine the different approaches illustrated above.

An improved management of the components would lead to a reduced power consumption, but would result in a significant increase in the number of ON/OFFoperations of the components.

Management of the cooling loads can lead to a significantly reduced power consumption without increasing the number of operations, but for reallife implementation, the degree of load management should be limited. Even though many of the consumers are in seemingly random operation, the cooling loads are strongly tied to the operation of the integrated brewery. For large values of load management, it is necessary to reconsider the operation of the total brewery. This is not realistic for an existing brewery. However, an advanced management strategy for the components would recuce the required degree of load management, as the plant can be operated in several more high-efficiency load points than with a simple management strategy.

By inspection of the many results, a practical strategy has been deduced. A significant reduction of the annual power consumption is obtainable when the plant design optimized for advanced management of the components is combined with $20 \%$ load management and an management strategy allowing one small screw compressor to alternate between the two utility systems. With this design and operation, the weekly power consumption would be $110.0 \mathrm{MWh}$ in August and 36.3 MWh in February, giving an annual reduction of $10.8 \%$

With this design and operation, the COP will vary during the week as shown in figure 7.

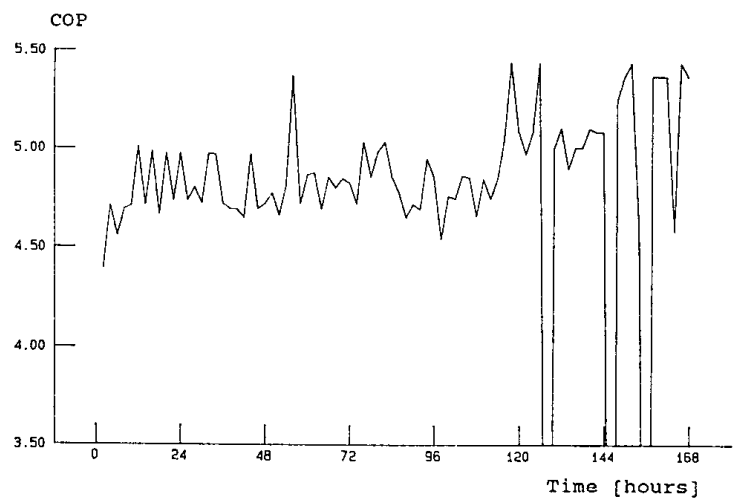

Figur 7. CP variation for the refrigeration plant during a week in August. Optimized design and operation, $20 \%$ load management.
By this combination of component management and load management, the weekly number of ON/OFFoperations of the screw compressors is approximately 50 \& higher than the present numbers, which is considered as acceptable. The number is far less than with the use of a fully advanced management strategy and illustrates the importance of load management.

\section{CONCLUSION}

A mathematical model has been applied to the study of the refrigeration plant in a brewery.

The usefullness of such a model is demonstrated through the results in which the improvements abtainable by design optimization, improvements in operational strategy and load management are weighed against the increased complexity of design and operation of the plant.

The study demonstrate the potential of a management of the numerous consumers in the plant. By a combination of design optimization, improved operational strategy for the components, and load management, electricity savings of $10 \%$ is found to be practically obtainable as compered to an idealized target of $15 \%$.

\section{REFERENCES}

[1] Nielsen, F.: "Exergy Analysis, Aspects of their Practical Use", Ph.D Thesis, Report RE 83-5, Laboratory for Energetics, The Technical University of Dermark, 1983. ISBN 87-7475-048-8.

[2] Iinnhoff, B.: "User Guide on Proces Integration for the Efficient use of Energy", The Institution of Chemical Engineers, 1985. ISBN 0-85295-156-6.

[3] Gaggioli, R.A. et all.: "Computer-Aided Engineering of Energy Systems", volume 1,2,3. papers presented at the winter annual meeting of The American Society of Mechanical Engineers, Anaheim, California, December 1986.

[4] Gurlev, J.: "Analysis, Optimization and Simulation of the Energy System at the Tuborg brewery", Laboratory for Energetics, Master Thesis PE-87-3, The Technical University of Demmark, 1987 (in Danish).

[5] Vidal, R.V.V.: "Notes on Static and Dynamic optimization", IMSOR, The Technical University of Dermark, 1984. 